УАK $323(470+571)$

ББК 66.3(2Pос)

DOI 10.22394/1682-2358-2019-5-51-60

D.V. Akaev, Candidate of Sciences (Sociology), Docent of the Sociology and Social Policy Department, Povolzbsky Institute of Management named after P.A. Stolypin, Branch of the Russian Presidential Academy of National Economy and Public Administration

\section{NON-PROFIT ORGANIZATIONS IN THE SOCIAL AND POLITICAL LANDSCAPE OF A REGION (By the Example of the Saratov Region)}

The results of the authorial study of the current state and development problems of socially oriented non-profit organizations in the Saratov region are analyzed. By the example of empirical research materials, conclusions about the current agenda and general trends in the development of the non-profit sector of the social and political landscape of the Saratov region are drawn.

Key words and word-combinations: socially oriented NGOs, non-profit sector, regional landscape, civil society development, Saratov region.
А.В. АкаеВ, кандидат сочиологичесих наук, доцент кафедрь сочиологи и сочиальной политики Поволжского института утравления - филиала Российской академии народного хозяйства и государственной службь при Президенте РФ (email:d_akaen@mail.ru)

\section{НЕКОММЕРЧЕСКИЕ ОРГАНИЗАЦИИ В СОЩИААЬНО- ПОАИТИЧЕСКОМ ПРОСТРАНСТВЕ РЕГИОНА (на примере Саратовской области)}

Аннотация. Анализируются результаты авторского исследования современного состояния и проблем развития социально ориентированных некоммерческих организаций Саратовской области. На примере материалов эмпирических исследований делаются выводы об актуальной повестке дня и общих тенденциях развития некоммерческого сектора общественно-политического пространства Саратовского региона.

Ключевые слова и словосочетания: социально ориентированные НКО, некоммерческий сектор, региональное пространство, развитие гражданского общества, Саратовская область.

B

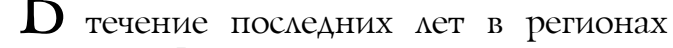
Российской Федерации ведется работа по государственной подАержке сектора соци- 
ально ориентированных некоммерческих организаций («третьего» сектора). Промежуточные результаты и достижения различных региональных программ подАержки выглялят неравномерно, что обусловлено как экономической региональной спецификой, так и особенностями изначально сложившейся инфраструктуры подАержки [1]. Такие территории, как г. Москва, Московская область, г. Санкт-Петербург, Краснодарский край, Нижегородская и Самарская области, Красноярский край, Новосибирская, Свердловская и Тюменская области, в последние годы демонстрируют эффективную работу некоммерческого сектора на базе своих региональных пространств.

Безусловно, наблюдаются попытки активизации проџесса выравнивания среднестатистических регионов до уровня мидеров. ОАнако до сих пор Аислокаџия некоммерческой организации в значительной степени определяет вероятность ее выживаемости, возможности, масштабность деятельности, набор содержательных и функциональных качеств [2] .

Саратовская область - российский регион с активным социально-политическим пространством и широким представительством общественной инициативы акторов. В опубликованном в декабре 2018 г. Рейтинге субъектов Российской ФеАерации по итогам реализации механизмов подлержки социально ориентированных некоммерческих организаций и соџиального преАпринимательства за 2017 г., составленном Минэкономразвития, Саратовская область занимает скромную 81-ю строчку с итоговым количеством рейтинговых бамлов 10,24 [3]. Предварительные результаты 2018 г. в целом анамогичны, Ааже условное место в рейтинге практически не изменилось (80-е против 81-го годом ранее) [4]. Подобное расхождение межАу активностью некоммерческого сектора региона и низкими количественными показателями побудицо провести комплексное соџиологическое исследование по проблемам развития НКО на территории Саратовской области. Прошедшее с февраля по июнь 2019 г. исследование включало экспертный опрос руководителей НКО Саратовской области $(N=240)$ и серию фокус-групповых интервью преАставителей НКО [5] .

СО НКО в Саратовской области малочисленны по количеству работающих в них сотрудников. Наибольшее распространение имеет группа организаций, в которых работает 1-3 постоянных сотрудника (44\%) (таблица).

Распределение ответов на вопрос

«Сколько постоянных сотрудников работает в вашей организаџии?»

\begin{tabular}{|l|c|}
\hline Показатели & $\%$ \\
\hline Нет & 11 \\
$1-3$ & 44 \\
$4-10$ & 30 \\
11 и больше & 15 \\
Всего & 100
\end{tabular}


Наиболее часто без постоянных сотрудников СО НКО обходятся, осушествляя деятельность в таких сферах, как здравоохранение, профикактика и охрана здоровья граждан, пропаганда здорового образа жизни, физическая культура и спорт (25\%); деятельность в сфере патриотического, в том числе военно-патриотического, воспитания гражАан Российской Федерации (18\%). Малочисленный персонал НКО (1-3 человека) наиболее характерен Аля организаций, работающих в сферах подготовки населения к преодолению посмеАствий и оказания помощи пострадавшим в результате стихийных беАствий, экологических, техногенных катастроф (51\%) и развития межнационального сотрудничества, сохранения и защиты самобытности, культуры, языков и традиџий народов Российской Федераџии (42\%); осуществмяющих деятельность в области культуры, искусства, улучшения морально-психологического состояния граждан (37\%); охраны окружающей среды (26\%). При этом самые многочисленные с точки зрения обеспеченности постоянными сотрудниками НКО (11 человек и более) наблюдаются в таких направлениях, как содействие повышению мобильности трудовых ресурсов (41\%); профилактика социально опасных форм поведения гражАан, мероприятия по медицинской реабилитации и соџиальной реабилитации, соџиальной и трудовой реинтеграции миџ, осуществцяющих незаконное потребление наркотических средств или психотропных веществ (24\%). Совсем не представлены крупные НКО в направлении соџиальной и культурной адаптаџии и интеграџии мигрантов, зато более половины организаций этого направления (58\%) имеют от 4 Ао 10 постоянных сотрудников.

Около Авух третей НКО считают, что их деятельность связана с оказанием услуг. Наиболее распространенным видом услуг являются соџиально-бытовые, направленные на подлержание жизнедеятельности граждан в быту $-27 \%$ организаций работают в этом направлении. Чуть меньше, по $25 \%$ организаций, оказывают соџиально-педагогические услуги, направленные на профикактику отклонений в поведении клиентов, формирование у них позитивных интересов, в том числе в сфере досуга, и соџиально-правовые услуги, связанные с оказанием юридической помощи, защитой законных прав и интересов граждан. В четверку наиболее попумярных ответов попали соџиально-медицинские ускуги, направленные на подлержание и улучшение здоровья граждан $(23 \%)$.

В наименьшей степени представлены организации, оказывающие срочные социальные услуги (8\%), и Аругие, не вошедшие в предложенный список услуг (научно-исследовательские, физкультурно-спортивные, культурно-просветительские и т.п.)

Корреляџию межАу услугами, предоставмяемыми НКО, и обращениями граждан далеко не во всех случаях удается выявить. Во многом так происходит потому, что понятия «ускуга» и «направление деятельности» в сознании руководителей и сотрудников СО НКО нередко тождественны, хотя методомогически это разные форматы работы. Организация может заниматься опреАеленным видом деятельности, полезным Аля общества в целом, но предоставцять ускуги отдельным гражданам в совершенно другом формате и значении. Необходимо проведение методических семинаров, а нередко и сопровожде- 
ние со стороны ресурсных центров, помогающих НКО приводить свою Аеятельность в соответствие с рыночными потребностями населения.

С какими трудностями сталкиваются СО НКО Саратовской области, выступая в роли поставщика соџиальных услуг? Этот вопрос ставит в тупик большинство респондентов. 39\% ответивших затрудняются Аать на него ответ, что свидетельствует об отсутствии у некоммерческих организаций реального опыта предоставления услуг на возмездной основе (участие в контрактной системе, участие в реестре поставщиков соџиацьных услуг, соџиальное преАпринимательство). Большинство респондентов, считающих, что их организации оказывают услуги, безусловно, ведут определенную работу, но, как правило, она направлена «на общество в целом», без конкретного адресата, получателя усмуги, который может спросить о конечном результате. Именно поэтому такой критерий оценки эффективности СО НКО, как «количество благополучателей и участников мероприятий», представмяется субъектам третьего сектора в Ава раза важнее, чем «благодарности и отзывы благополучателей».

Среди респондентов, ответивших на вопрос о трудностях, мидирует позиция, набирающая 26\% ответов: «наша услуга не внесена в реестр услуг». За ней располагаются «не можем получить компенсацию за предоставленные услуги» (22\%) и «не соответствуем стандарту услуги» (15\%). При этом 12\% организаций не сталкиваются ни с какими трудностями

В сложившейся ситуации можно сАелать вывод: необходимо планомерное информаџионно-образовательное сопровождение процессов перехода СО НКО на модель оказания услуг начиная с законодательных основ и заканчивая проработкой индивидуальных Аля каждой организаџии амгоритмов преАоставцения услуг. Осуществить эту работу под силу методическим ресурсным центрам.

Следуя плану исследования, экспертам предстояло оџенить разцичные способы мер регулирования в таких сферах, как улучшение финансового и имущественного положения, расширение образовательных и консультационных услуг, а также улучшение положения СО НКО региона в направлении развития информационных ресурсов.

УАучшению финансового положения СО НКО, по мнению респондентов, в наибольшей степени будут способствовать следующие традиџионные способы: увеличение финансирования из средств государственного бюджета (55\%), привлечение благотворительных средств бизнеса (42\%), освобождение СО НКО от упматы части налога, равно как и введение налоговых мьгот Аля СО НКО Саратовской области (42\%). Чуть менее попумярной мерой назывались расширение практики применения государственного и муниципального заказа Аля СО НКО (37\%) и увеличение финансирования из бюджетов муниџипацьных образований (32\%). В меньшей степени респонденты питают надежАу на увеличение размеров грантов и продолжительности выполения проектов (29\%), привлечение средств населения, Аобровольные взносы и пожертвования граждан (17\%) и развитие практики оказания платных услуг (14\%). Непопулярными мибо малоэффективными, с точки зрения представителей СО НКО, явцяются увеличение числа фондов местных сообществ, привлечение 
средств иностранных доноров и увеличение чиенских взносов.

Таким образом, СО НКО преимущественно делают ставку на государство и именно от него ожидают укучшения своего финансового положения. Маркетинговые способы увеличения финансирования организаций реже соответствуют ожиданиям и вызывают некоторые сомнения в их применимости.

Аля улучшения имушественного положения СО НКО респонденты считают необходимым прежде всего Аоработать нормативно-правовую базу об условиях предоставления государственного и муниципацьного имущества Аля нужА СО НКО (51\%). Необходимо отметить, что проблема необеспеченности имуществом Аця общественных организаций явцяется самой острой, Аажке вопрос финансовой обеспеченности уходит на второй план. Имущественная подлержкка СО НКО мишь декларирована, но не предложен механизм безвозмездной передачи помещений Амя осуществления соџиально значимой Аеятельности.

Еще одной мерой, призванной улучшить имущественное положение СО НКО, можкет стать создание общедоступных фондов Авижимого имущества (транспорт, оборудование) с возможностью его комлективного использования. $37 \%$ респондентов считают правильным Авижение в этом направлении. Третья по популярности мера - опубликование реестров Аоступного госуАарственного и муниципального недвижимого имушества (31\%). Как правимо, такие реестры не явцяются «информацией Аля служебного пользования», однако нередко предлагаемые помешения не соответствуют элементарным нормам благоустройства, в них необходимо вкладывать дополнительные средства, при этом отсутствуют гарантии, что помещение останется за организаџией на относительно Алительный срок. В несколько меньшей степени выбор можится на развитие сети коворкинг-центров и пространств комлективного доступа (23\%). Невысокую попумярность этой идеи можно объяснить тем, что в большинстве случаев взаимодействие межАу НКО не носит постоянного системного характера.

Среди возможных мер, направленных на расширение образовательных и консультационных услуг Аля СО НКО, на первый план выходит «расширение сети ресурсных центров Аля СО НКО на регионацьном и муниципальном уровне» (40\%). Близкие значения набирают следующие меры: «увеличение количества существующих образовательных программ, семинаров, курсов повышения квамификации дия СО НКО» (32\%), развитие информационно-консультативных интернет-ресурсов, Аистанџионного образования и консультирования (30\%) и «создание тематических ресурсных центров на базе сильных СО НКО» (27\%). Малопопулярной оказалась мера, направленная на расширение тематики методических семинаров, обучающих программ и стажкировок дия СО НКО. Вероятно, существующей минейки образовательных мероприятий в основном Аостаточно, и усилия ресурсным и методическим центрам стоит направить на охват большей аудитории. Напомним, что, оџенивая уровень развития ресурсных центров, респонденты чаще отмечали удовметворенность их качеством, но не количеством.

Уцучшению положения СО НКО в направлении развития информацион- 
ных ресурсов в наибольшей степени будет способствовать проведение профессиональных конференций, форумов и Аругих событий, направленных на презентацию цучших практик и обмен опытом. Этот вектор развития подАерживает $46 \%$ респондентов. В несколько меньшей степени НКО считают эффективным увеличение специализированных интернет-ресурсов (37\%) и специальные информационные проекты в СМИ, посвященные тематике третьего сектора (36\%). Расширение контактов в профессионацьной среле (34\%) подАержало немного меньше экспертов, отдав предпочтение новому формату опосредованного онацйн-общения. Но неформальное общение остается весомым в деятельности некоммерческого сектора, поэтому более трети респондентов выделяют его среди важных элементов. Увеличение форматов очного взаимодействия неоднократно подчеркивалось в разных исследованиях и можкет нести в себе решение проблемы разобщенности и несистемности сотрудничества межау НКО.

Такая мера, как увемичение числа специализированных периодических изАаний дмя СО НКО, наименее популярна. Это свидетельствует о том, что печатные периодические издания НКО постепенно уходят в прошлое, большинство руководителей и сотрудников черпают оперативную информацию из Сети. Подавцяющее большинство НКО уверены, что предоставцяют услуги, при этом явно испытывают дефицит информации в этих вопросах.

Оценивая разцичные предложенные меры по улучшению своего положения, СО НКО преимущественно делают ставку на проверенные традиционные способы. В частности, улучшение финансового положения ожидается прежде всего от государства. Маркетинговые способы увеличения финансирования организаций реже соответствуют ожиданиям и вызывают некоторые сомнения в их применимости.

Определив основную проблематику, выраженную в кратких ответах респондентов, согласно проработанной методологии авторы провели три фокусгрупповых интервью, с помощью которых получили возможность, во-первых, развернуть и более подробно уяснить проблемы СО НКО Саратовской обмасти, а во-вторых, верифицировать уже полученные результаты экспертного опроса. При этом у модератора фокус-групп к моменту проведения уже были предварительные данные опроса, которые использовались и дия построения хода Аискуссии.

Фокус-группы состоялись в мае - июне 2019 г. в Поволжском институте управления имени П.А. Столыпина - филиале РАНХиГС и аккумулировали мнение более сорока активных преАставителей некоммерческого сектора региона. Вопросы к каждому исследованию слегка варьировались дия выстраивания наибомее полной картины по всем направцениям с учетом процедурных моментов.

Прежке всего интересовац вопрос о том, как изменились в последние три года в Саратовской области условия Аля развития гражкданских иниџиатив. В основном в ответах экспертов отмечалось поступательное развитие иниџиатив снизу: «Коллеги, я считаю, что за последние три года, не сказать, что очень успешно, но какие-то подвижки б этом плане бьли сделань. Все-таки, например, поддерживаются наши некоммерческие организачи конкурсом суб- 
сидий. Все-таки он есть. Ава года его не бъго, по-моему. Ава, да. Но потом он снова возобновился - большой плюос».

Следующим аспектом, интересовавшим исследователей, было согласие с утверждением о том, что НКО содействуют развитию общественной иниџиативы и добровольчеству. При ответах на этот вопрос преобладали положительные оценки организаций: «Я согласна полностью. Хоть бьг нам и говорили свои примерьг не приводить, но вот буквально сегодня В полдевятого утра мьг начали проект совместныии...». "У НКО есть инструмент, если мьг говорим про действуюшие, активние, хорошие, крепкие НКО, которие имеют уже опьт, имеют образование, сотрудники чему-то учатся постоянно, какой-то опьгт с других регионов. Если вот это вот Все есть у конкретныхх организаций - они могут содействовать реально развитию общества дальше в нужном, хорочем, ключевом русле и привлекать ту же власть, тот же бизнес».

Еще одним интересующим аспектом стало выявление степени обеспеченности большинства саратовских НКО основными ресурсами. Спектр ответов в основном подтвердиц результаты анкетного опроса о недостаточной обеспеченности финансами и имушеством: «Я просто считаю, ито если есть ресурс административньй у человека, если, допустим, он занимает еше какую-то должность, то, конечно, тогда и НКО его более успешно, оно движется както вперед. Конечно, есть люди, которие принимают людей и инвалидов у себя дома, так как нет помещения. Или им предоставляются, допустим, помещения, которие нужно также отремонтировать. Это тоже нет ресурсољ. В основном содержать НКО, наверное, не очень всем по карману, но это реально тяжело». "Единственное, какие-то отдельно взятице НКО, коториге приближеньг к сильньгм мира сего или которие действительно вьигрьъвают грантьи, они что-то еще могут». "Мне помещение тоже власть дала. У меня там за все платят. И за телефон платят, и за помещение платят - nопробуй только не заплатить. Потому что еще и от руководства... Не Все, конечно, не Все Возможно, я все это понимаю.»

Участникам предлагалось также оџенить ситуащию, характеризующую взаимодействие социально ориентированных НКО. Ответы оказались разноплановыми в первую очередь за счет гетерогенности организаций и установившейся практики: «Только сотрудничество. Вот сейчас нет Натальи Викторовньг, мьг как раз-таки сотрудничаем. Она помогает онкобольньгм, и взросльмм, и детям 8 том числе. Аальше, мьи, например, сотрудничаем с фондом «Подари жизнь» и с «Русфондом». «Я не гоборю о том, ито есть конкуренция, да, мь все общаемся, и благодаря взаимодействию миг и существуель. «Я бы хотела добавить про партнерство НКО. Знаете, коллеги, взаимодействие только тогда хорошо, когда друг друга понимают руководители. Они понимают, ито они дополняют друг друга, а не конкурируют. Если конкурируют, никакого взаимодействия не будет». "Аело В том, что мог живем с вами в обществе ринка, конкурениия на всех уровнях существует, это даже без вопросов. Иногда миг эту конкурениию обнаруживаем поздно, иногда мьг можем ее предугадать, и это совершенно 
естественно».

$\mathrm{O}_{А и н}$ из завершающих вопросов касался получения новых знаний: в каких семинарах было бы интересно принять участие вам как представителям НКО, чему обучиться? Ответы в основном подтвердили данные экспертного опроса с определенной долей детализаџии: «По фандрайзингу. Привлечение средств. Я вот лично сльпиала, ито В Саратове обучаноие семинари проводились». «А вот тимбилдинг, он поможет». «...Вот можно семинар-обучение по теме доверия, потому ито даже здесь это чувствуется, ито нам нужно через тимбилдинг или какие-то другие методики, мьг должнь узнавать друг друга, мьг должны взаимодейстьовать не только в рамках кругльгх столов и семинаров, где мы там слуиаем. Это какие-то активньге методики, которье в конечном счете должнь работать на доверии между НКО, потому что если мог друг с другом не можем взаимодействовать, то или не хотим, или не знаем каю». «...Поэтому я би... сейчас... особого внимания не уделила какомуто из направлений. Знаю, что всегда нужно каждици вопрос прорабатьгать, даже если кажется, что все хорошо знаем про налоговие законодательстьа, хорошо знаем про капитальи, вот недавно отучились. Все это развивается, и останаһливаться нельзя, надо постоянно учиться, даже руководителям и сотрудникам НКО сфери, чтоби действительно в ногу со временем. Может бътьь, больше каких-то, знаете, даже... командньхх тренинго, на что НКО очень мало обращает вниманияь.

Проведенные фокус-групповые интервью с представителями некоммерческого сектора региона позволили довольно детально прояснить все аспекты функционирования СО НКО в региональном пространстве, получив эмпирическое подтверждение экспертному опросу, проведенному ранее. Основные проблемы некоммерческих организаций, связанные с имущественным комплексом и несистемным финансированием, получили экспертную оџенку, сформулированы предложения совершенствования сложившейся системы.

Подводя итоги анализа полученных данных по экспертному опросу и сравнивая данные с результатами проведенных фокус-групп, можно сделать некоторые общие выводы.

По сравнению с предыдущими годами текущая финансовая ситуация Аля СО НКО более благоприятна [6]. При этом финансовые поступцения от Аругих российских НКО весьма незначительны, что свидетельствует о невключенности основной части организаџий в сетевые структуры или проекты, то есть о недостаточной общей координированности действий в секторе.

Большинство преАставителей СО НКО считают, что Аля успешной деятельности третий сектор обеспечен основными ресурсами, но в недостаточной мере. В целом доли респондентов, считающих, что они обеспечены ресурсами, разнятся по категориям (10-41\%). Заметно кучшая картина вырисовывается в отношении образовательной и консультационной поддержкки ( $41 \%$ удовлетворенных уровнем поддержки), а также труда добровольцев (29\% считают себя обеспеченными этим ресурсом). В этих аспектах ресурсный потенциал в регионах относительно развит. Наиболее острая потребность может быть зафиксирована в отношении имушества $-28 \%$ категорически заявмяют, 
что не обеспечены данным видом ресурсов, а 52\% экспертов отметили, что обеспечены, но недостаточно. В отношении таких ресурсов, как финансирование, кадры, информационное сопровождение, наблюдается средний уровень удовлетворенности.

В практической деятельности большинство СО НКО нацелены на активизацию гражАан и популяризацию добровольчества, однако в силу складывающихся тенденций, дискурса и даже определенной моды мыслят себя и весь сектор в еше не сложившейся, несколько виртуальной реальности, в модели, в которой НКО предоставляют соџиальные услуги. В целом поА миссией НКО чаще всего представители третьего сектора понимают активизацию граждан, ресурсов территории на решение соџиальных проблем, развитие общественной инициативы и добровольчества (53,2\%). Чуть меньше половины респондентов выделяют оказание непосреАственной помощи уязвимым слоям населения, нуждаюшимся (45,3\%); создание инновационных механизмов решения социальных проблем (42,4\%); защиту прав и интересов граждан и их объединений, осуществление независимого контромя наА деятельностью органов власти и МСУ (41\%).

Немаловажным для развития некоммерческих организаџий явмяется их функционирование в социально-политическом пространстве региона. ЗАесь кАючевым моментом явмяется взаимодействие как с властными структурами регионального и муниципального уровней, так и налаживание взаимоотношений с местным бизнесом, позволяющее надеяться не только на финансирование государством. В фокусе ответов респондентов преобцадало позитивное отношение к сложившемуся продуктивному взаимодействию с органами власти (48\%), в половине случаев остались удовлетворены таким взаимодействием $32 \%$ респондентов. Взаимодействие СО НКО с бизнесом в Саратовской области не отличается подобным позитивным настроем - преобладающим ответом стало удовлетворение только в половине случаев ( $36 \%$ ответов), и Ааже негативный оттенок от такого взаимодействия получиц подлержкку $31 \%$ ответов респондентов. Учет сложной экономической ситуации как в государстве, так и в Саратовском регионе, позвомяет определить позиџию бизнеса по отношению к некоммерческому сектору не как принџипиальную, а связанную с объективными финансовыми затруднениями, заставмяющими оптимизировать расходы на непрофильную деятельность [6] .

Подавляющее большинство НКО уверены, что предоставцяют услуги, но при этом явно испытывают дефиџит информации в этих вопросах. Коррецяџию межАу услугами, предоставмяемыми НКО, и обращениями граждан в организации удается выявить далеко не во всех случаях. Во многом так происходит потому, что понятия «услуга» и «направление деятельности» в сознании руководителей и сотрудников СО НКО часто тождественны, хотя методологически это разные форматы работы. Организация может заниматься определенным видом деятельности, полезным для общества в целом, но предоставлять услуги отдельным гражданам совершенно Аругого рода и значения. 
В предлагаемых мерах по улучшению своего финансового положения СО НКО преимущественно делают ставку на государство, а Аля улучшения имушественного положения считают необходимым усовершенствовать нормативно-правовую базу в данной сфере. В развитии информаџионных ресурсов предполагается внедрение нового формата взаимодействия посреАством информационно-коммуникационных систем.

\section{Библиографический список}

1. Отчет по результатам исследования «Состояние сектора НКО в регионах Сибири». URL: http://nko.economy.gov.ru/Files/NewsDocuments/d1981c28-f7a1-4c72-9a75-5cc9ebd71c99.pdf

2. Семушенкова А.С. Статусно-ролевые характеристики некоммерческого сектора: дискрипция регионального пространства Республики Мордовия // Вестник Поволжского института управления. 2019. Т. 19, № 3. С. 65-77.

3. Результаты рейтинга субъъектов Российской Федерации по итогам реализации механизмов поддержки социально ориентированных некоммерческих организаций и социального предпринимательства, обеспечения доступа негосударственных (немуниципальных) поставщиков к предоставлению услуг в социальной сфере и внедрения конкурентных способов оказания государственных (муниципальных) услуг в социальной сфере за 2017 г. // Социально ориентированные некоммерческие организации России: Инфографика на основе данных Росстата. URL: http://nko.economy.gov.ru/portalnews/read/4606

4. Минэкономразвития России направлены в Правительство РФ итоги рейтинга субъектов Российской Федерации в 2018 г. URL: http://nko.economy.gov.ru/PortalNews/Read/5109

5. Акаев Д.В., Куликов В.М. Социально ориентированные НКО Саратовской области на рынке социальных услуг: современное состояние и проблемы развития. Саратов, 2019.

6. Мироненко Н.В. Контрактные отношения как основной инструментарий построения межсекторного социального партнерства в контексте взаимодействий НКО и населения // Среднерусский вестник общественных наук. 2014. № 4 (34). С. 131-141. 